\title{
Delivery of beclomethasone dipropionate from a spacer device: what dose is available for inhalation?
}

\author{
Christopher O'Callaghan, Megan Cant, Colin Robertson
}

\begin{abstract}
Background - It is common for inhaled steroids to be delivered through a large volume spacer device. Comparatively little is known about how this practice affects the dose of drug received by patients compared with drug delivered directly from a metered dose inhaler.

Methods - The amount of beclomethasone dipropionate, contained in particles of various size, available for inhalation from a $750 \mathrm{ml}$ polycarbonate spacer (Volumatic) was determined by impinger measurement and high performance liquid chromatography. Three strengths of metered dose inhalers were studied $(50 \mu \mathrm{g}$, $100 \mu \mathrm{g}$, and $250 \mu \mathrm{g} /$ actuation). The effect of multiple actuations of beclomethasone dipropionate into a Volumatic spacer, and increasing residence times of drug within the spacer before inhalation, on the amount of drug available to the patient for inhalation was determined.
\end{abstract}

Results - The amount of beclomethasone dipropionate in particles $<5 \mu \mathrm{m}$ when delivered by a spacer device or directly from a metered dose inhaler was similar. The total amount of beclomethasone dipropionate available for inhalation per actuation decreased by $20 \mu \mathrm{g}$ with the $50 \mu \mathrm{g}$ inhaler, $48 \mu \mathrm{g}$ with the $100 \mu \mathrm{g}$ inhaler, and $161 \mu \mathrm{g}$ with the $250 \mu \mathrm{g}$ inhaler, when given via the spacer compared with delivery directly from a metered dose inhaler. There was a progressive decrease in drug available for inhalation per actuation as the number of actuations into the spacer increased, for all strengths of beclomethasone dipropionate tested. A progressive decrease in drug recovered per actuation was also seen with increasing residence times of drug within the spacer before inhalation.

Conclusions - Use of the spacer device significantly reduced the amount of nonrespirable beclomethasone dipropionate available for inhalation. The amount of beclomethasone dipropionate within respirable particles decreased considerably following multiple actuations into the spacer and with increasing residence times within the spacer before inhalation. When given via a spacer device beclomethasone dipropionate should be inhaled immediately after actuation and multiple actuations into the device should be avoided.

(Thorax 1994;49:961-964)
Spacer devices have been developed to combat problems of high oral deposition and coordination difficulties associated with metered dose inhalers. ${ }^{1}$ Although large volume spacers are in widespread use, little is known of the dose available from spacer devices compared with that from metered dose inhalers. ${ }^{2}$ Knowledge of the steroid dose available to the patient for inhalation from a metered dose inhaler or via a spacer device is important in view of dose dependent side effects ${ }^{34}$ and may allow a more meaningful comparison between different steroid delivery methods. It may be preferable to express drug dosage as that available for inhalation from the spacer device as well as that discharged from the metered dose inhaler. This dose will include the amount of drug impacting in the throat and being swallowed, as well as that inhaled into the lower respiratory tract.

The purpose of this study was to determine (1) the total dose of beclomethasone dipropionate and the dose contained in particles likely to reach the airways $(<5 \mu \mathrm{m})$ available for inhalation from a $750 \mathrm{ml}$ spacer device (Volumatic) using the $50 \mu \mathrm{g}, 100 \mu \mathrm{g}$, and $250 \mu \mathrm{g}$ strength metered dose inhalers; (2) the effect of an increased residence time of drug within the spacer device on the available therapeutic dose; and (3) the effect of multiple actuations of beclomethasone dipropionate into the spacer device, before inhaling the aerosol cloud, on the available therapeutic dose.

\section{Methods}

PARTICLE SIZE ANALYSIS

A multistage liquid impinger was used to assess the aerodynamic particle size distribution of the aerosol cloud. ${ }^{5}$ The impinger, running at $60 \mathrm{l} / \mathrm{min}$, was calibrated by sampling an aerosol of dibutyl phthalate droplets that had been sized by a laser particle sizing device (Malvern 3600, Malvern Ltd, UK). A 50\% cut off diameter was derived for each stage of the device and was expressed in terms of aerodynamic diameter. The aerodynamic diameter of a droplet is the diameter of a unit density spherical particle with the same settling velocity as the droplet in question. The mean (SD) humidity over the study period was $55(3) \%$, and the mean temperature of the room was $23(2)^{\circ} \mathrm{C}$.

\section{TEST METHOD}

The following experiments were performed using $50 \mu \mathrm{g}, 100 \mu \mathrm{g}$, and $250 \mu \mathrm{g}$ metered dose inhalers (Allen and Hanburys Ltd, UK). The 
mouthpiece of the metered dose inhaler was connected to the impinger with the aid of a small rubber sock and air was drawn through the apparatus at a flow of $60 \mathrm{l} / \mathrm{min}$. The aerosol was then discharged through the impinger on 10 occasions for each study to facilitate the chemical assay procedure. The metered dose inhaler was shaken between each actuation. For this experiment and each of the experiments outlined below, four separate impinger runs were performed. Results are expressed as the mean (SD) of these experiments.

In the case of the Volumatic spacer device (Allen and Hanburys Ltd), the metered dose inhaler (Glaxo Ltd) was discharged into the device and, after a delay of approximately one second, the mouthpiece of the Volumatic spacer was connected to the impinger and the aerosol drawn from the spacer.

The first actuation from the metered dose inhaler was discarded for each experiment and no more than 20 actuations were used from the same inhaler. The time interval between actuations was approximately five seconds.

\section{MULTIPLE DOSING}

Beclomethasone dipropionate was discharged into the spacer, after which the metered dose inhaler was removed and shaken and a further dose of beclomethasone dipropionate was fired into the spacer. One second later the device was connected to the impinger and the aerosol drawn from the device. The dose available to the patient following two actuations into the device could therefore be assessed. This was repeated using three, four, five, and 10 actuations.

\section{EFFECT OF RESIDENCE TIME DELAY}

The residence time is the time period between actuation of the metered dose inhaler into the spacer device and connection to the multistage liquid impinger. Residence times of one second, $5,10,20,30,45$, and 60 seconds were examined. For example, one actuation was delivered to the Volumatic and five seconds later the drug was sucked from it through the impinger.

\section{DRUG ASSAY}

The impinger samples containing beclomethasone dipropionate were collected in methanol/water (80/20) and, using high performance liquid chromatography (HPLC), were assayed against a range of known concentrations of beclomethasone dipropionate standards in methanol/water (80/20) prepared from beclomethasone dipropionate powder $(98.5 \% \mathrm{w} / \mathrm{w})$. The results were calculated on a mean peak height basis, standard mean response factors being used.

Using the data acquired from the multistage impinger, together with the $50 \%$ cut off diameter for each stage of the device, a plot of aerodynamic size against cumulative percentage undersize was constructed. From this graph the following measurements were made: (1) mass median aerodynamic diameter (MMAD) - that is, the diameter of droplet such that half of the aerosol mass is contained in smaller droplets and half in larger droplets; and (2) geometric standard deviation (GSD) which is the ratio of the $84 \cdot 1 \%$ diameter: $50 \%$ mass median aerodynamic diameter - the value of the geometric standard deviation is a measure of the width of the droplet distribution. The amount of drug contained in particles $<3 \mu \mathrm{m}$ and $<5 \mu \mathrm{m}$ was also determined.

After each study the spacer device and actuator were also washed out to collect beclomethasone dipropionate deposited there. Thus, the total dose from the metered dose inhaler could be determined.

A known concentration of beclomethasone dipropionate was assayed on several occasions to determine the coefficient of variation of the assay. Humidity and temperature were measured during the study period.

\section{Results}

The total dose of beclomethasone dipropionate and that contained in particles of $<3 \mu \mathrm{m}$ and $<5 \mu \mathrm{m}$ diameter delivered directly from the various strength metered dose inhalers is shown in the table. There was a $20 \mu \mathrm{g}, 48 \mu \mathrm{g}$, and $161 \mu \mathrm{g}$ reduction in total dose for the $50 \mu \mathrm{g}$, $100 \mu \mathrm{g}$, and $250 \mu \mathrm{g}$ strength beclomethasone dipropionate inhalers, respectively, when given by the Volumatic spacer compared with delivery directly from a metered dose inhaler.

When a spacer was used drug available for inhalation, contained in particles $<5 \mu \mathrm{m}$, decreased by $0.5 \mu \mathrm{g}$ and $7 \mu \mathrm{g}$ per actuation for the $50 \mu \mathrm{g}$ and $100 \mu \mathrm{g}$ metered dose inhalers respectively. An increase of $3 \mu \mathrm{g}$ per actuation was seen with the $250 \mu \mathrm{g}$ metered dose inhaler.

Figure 1 shows the effects of multiple actuations of beclomethasone dipropionate in the spacer device on the total amount available for inhalation per actuation, and that contained in particles $<3 \mu \mathrm{m}$ and $<5 \mu \mathrm{m}$ diameter. There was a progressive decrease in drug recovered per actuation as the number of actuations into the spacer device before inhalation in-

Total amount of beclomethasone dipropionate (BDP) available for inhalation and that contained in particles $<5 \mu m$ or $<3 \mu \mathrm{m}$ when delivered directly from a metered dose inhaler (MDI) or via a Volumatic spacer device

\begin{tabular}{|c|c|c|c|c|c|c|}
\hline \multirow[t]{2}{*}{$\begin{array}{l}\text { Strength of } \\
M D I(\mu g)\end{array}$} & \multicolumn{2}{|c|}{$\begin{array}{l}\text { Total } B D P(\mu g) \text { available for } \\
\text { respiration }\end{array}$} & \multicolumn{2}{|c|}{$B D P(\mu g)$ in particles $<5 \mu m$} & \multicolumn{2}{|c|}{$B D P(\mu g)$ in particles $<3 \mu m$} \\
\hline & $M D I$ & $M D I+$ spacer & $M D I$ & $M D I+$ spacer & $M D I$ & $M D I+$ spacer \\
\hline $\begin{array}{r}50 \\
100 \\
250\end{array}$ & $\begin{array}{c}37(2) \\
78(10) \\
246(10)\end{array}$ & $\begin{array}{l}17 \cdot 5(2) \\
30 \cdot 5(3 \cdot 3) \\
85(9)\end{array}$ & $\begin{array}{l}11 \cdot 5(\cdot 1 \cdot 8) \\
29(5) \\
42 \cdot 3(6)\end{array}$ & $\begin{array}{l}11(2 \cdot 1) \\
22(2 \cdot 9) \\
46(5)\end{array}$ & $\begin{array}{r}3 \cdot 8(2 \cdot 3) \\
8 \cdot 1(1 \cdot 3) \\
15 \cdot 9(2 \cdot 5)\end{array}$ & $\begin{array}{c}3 \cdot 8(0 \cdot 8) \\
9 \cdot 25(0 \cdot 9) \\
13(3)\end{array}$ \\
\hline
\end{tabular}



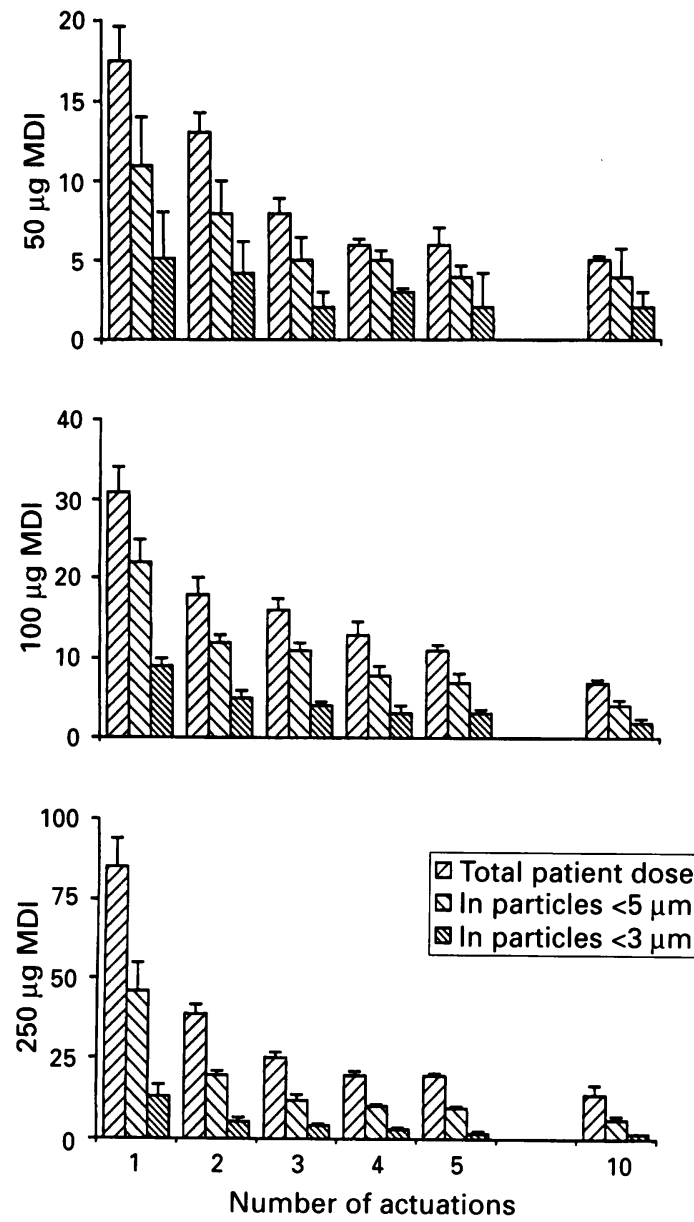

Figure 1 Effect of number of actuations into the spacer device on the total dose of beclomethasone dipropionate available for inhalation and that contained in particles $<5 \mu \mathrm{m}$ and $<3 \mu \mathrm{m}$ diameter. Results are expressed as the dose of beclomethasone dipropionate available for inhalation from metered dose inhalers (MDIs) of 50,100, and $250 \mu \mathrm{g}$ strength actuation. Values are mean (SD).

creased. The MMAD (GSD) measured after one actuation $(50 \mu \mathrm{g}=3.8 \mu \mathrm{m}(1 \cdot 8) ; 100 \mu \mathrm{g}=$ $3.8 \mu \mathrm{m}(2) ; 250 \mu \mathrm{g}=5 \mu \mathrm{m}(1 \cdot 5))$ was similar to that measured after 10 actuations $(50 \mu \mathrm{g}=$ $3.7 \mu \mathrm{m}(1.6) ; 100 \mu \mathrm{g}=4.5 \mu \mathrm{m}(1.9) ; 250 \mu \mathrm{g}=$ $5 \mu \mathrm{m}(1 \cdot 5))$.

Figure 2 shows the effect of increasing residence time of drug within the spacer on the total amount of beclomethasone dipropionate available for inhalation per actuation, and that contained in particles $<3 \mu \mathrm{m}$ and $<5 \mu \mathrm{m}$ diameter. Drug available for inhalation decreased for all strengths of beclomethasone dipropionate tested as residence time increased. The MMAD (GSD) measured one second after actuation $(50 \mu \mathrm{g}=$ $3.8 \mu \mathrm{m}(1.8) ; \quad 100 \mu \mathrm{g}=3.8 \mu \mathrm{m}(2) ; \quad 250 \mu \mathrm{g}=$ $5 \mu \mathrm{m}(1 \cdot 5))$ was greater than that measured 60 seconds after actuation $(50 \mu \mathrm{g}=3.4 \mu \mathrm{m}(1 \cdot 8)$; $100 \mu \mathrm{g}=3.5 \mu \mathrm{m}(1 \cdot 2) ; 250 \mu \mathrm{g}=4.2 \mu \mathrm{m}(1 \cdot 6))$.

The total mean recovery of beclomethasone dipropionate per actuation over the study period was $42(2) \mu \mathrm{g}$ with the $50 \mu \mathrm{g}$ inhaler, $84(5) \mu \mathrm{g}$ with the $100 \mu \mathrm{g}$ inhaler, and $246(10) \mu \mathrm{g}$ with the $250 \mu \mathrm{g}$ inhaler.

The coefficient of variation of the assay of beclomethasone dipropionate in our laboratory was $3 \%$.

Discussion

We have determined the actual dose of beclo-
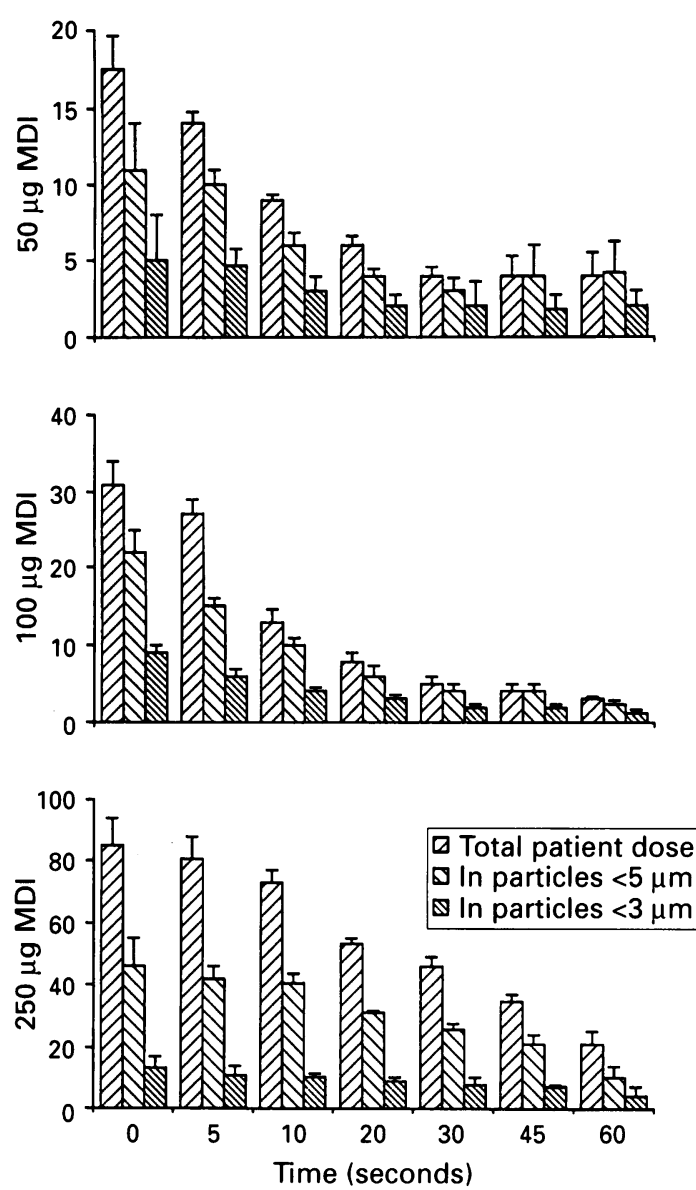

Figure 2 Total dose of beclomethasone dipropionate available for inhalation from the spacer device per actuation from metered dose inhalers (MDIs) of 50, 100, and $250 \mu \mathrm{g}$ strength actuation and that contained in particles $<5 \mu \mathrm{m}$ and $<3 \mu \mathrm{m}$ diameter following various residence times within the spacer. Values are mean (SD).

methasone dipropionate available for inhalation from a spacer device which is essential to evaluate dose dependent side effects and to allow meaningful comparison between different steroid delivery methods.

Studies by Farrer et $a l^{4}$ and Brown et $a l^{3}$ have confirmed, clinically, the importance of spacer devices in reducing adrenal suppression. This is consistent with our findings that the Volumatic spacer significantly reduced the total dose of beclomethasone dipropionate reaching the patient, while having little effect on the dose contained in particles likely to be inhaled into the lungs. Multiple actuations of the metered dose inhaler into the spacer before inhalation resulted in a significant decrease in the amount of drug recovered in particles within the "respirable range".

More than one actuation of drug into a spacer device before inhalation should be avoided. Subsequent actuations result in a rapid rise in pressure within the spacer which causes turbulent deposition of particles from earlier actuations onto the spacer walls. In addition, the higher concentration of particles with multiple actuations may make collisions and agglomeration more likely, thus increasing particle size.

Many studies have used the technique of multiple actuations of steroid aerosol into a 
spacer device before inhalation ${ }^{67}$ without considering the effect on the dose of drug available for inhalation. Similarly, a dose of inhaled steroids above which tests for adrenal suppression should be considered has been suggested without taking into account the method of drug delivery. ${ }^{8}$

As shown with disodium cromoglycate delivered by spacer device, ${ }^{9}$ even a short delay between actuation of a beclomethasone dipropionate metered dose inhaler and inhalation considerably reduced the total dose and amount of drug in small particles available for inhalation. Reduction in available drug with time will be more important for young children who take small breaths and more than one inhalation, and hence take a longer time to clear the spacer. Similarly, carers administering the drug to a child or elderly person should be sure to actuate the metered dose inhaler when the patient is ready.

Caution must be taken when comparing the dose available for inhalation in particles $<5 \mu \mathrm{m}$ diameter given directly from the metered dose inhaler with delivery from the spacer device. The artificial throat of an impinger device poorly represents the throat of patients. In addition, the device is run at a suction of $60 \mathrm{l} /$ min which may overestimate the amount of drug contained in particles $<5 \mu \mathrm{m}$ when the metered dose inhaler is used alone. As very little drug impacts in the throat when given via a spacer device, the amount of drug available for inhalation from spacer devices will more closely represent actual inhalation.

In summary, use of a standard $750 \mathrm{ml}$ spacer device is advisable to increase the amount of drug delivered to the lungs while decreasing the total steroid dose to the patient. When given via a spacer device the drug should be inhaled immediately after actuation and multiple actuations into the device are best avoided. Optimum use of spacer devices could improve the effectiveness of asthma management and reduce the wastage of expensive drugs resulting from poor inhaler and spacer technique.

1 Newman SP, Moren F, Pavia D, Little F, Clarke SW. Deposition of pressurised suspension aerosols inhaled through extension devices. Am Rev Respir Dis 1981;124:317-20.

2 O'Callaghan C. Particle size of beclomethasone dipropionate produced by two nebulisers and two spacer devices. Thorax 1990;45:109-11.

3 Brown HP, Blundell G, Greening AP, Crompton GK. Do large volume spacer devices reduce the systemic effects of high dose inhaled corticosteroids? Thorax 1990;45:736-9.

4 Farrer M, Francis AJ, Pearce SJ. Morning serum cortisol concentration after $2 \mathrm{mg}$ inhaled beclomethasone dipropionate in normal subjects: effect of a $750 \mathrm{ml}$ spacing device. Thorax 1990;45:740-2

5 Bell JH, Brown K, Glasby J. Variation in delivery of isoprenaline from various pressurised inhalers. If Pharm (Suppl) 1973;25:32-6.

6 Hummel S, Lehtonen L and Study Group. Comparison of oral steroid sparing by high dose and low dose inhaled steroid in maintenance treatment of severe asthma. Lancet 1992;340:1483-7.

7 Noble V, Ruggins NR, Everard ML, Milner AD. Inhaled budesonide for chronic wheezing under 18 months of age. Arch Dis Child 1992;67:285-8.

8 Priftis K, Milner AD, Conway E, Honour JW. Adrenal function in asthma. Arch Dis Child 1990;65:838-40.

9 O'Callaghan C, Lynch J, Cant M, Robertson C. Improvement in sodium cromoglycate delivery from a spacer device by use of an antistatic lining, immediate inhalation, and avoiding multiple actuations of drug. Thorax 1993;48: 603-6. 